\title{
РЕСУРСНЫЕ ОГРАНИЧЕНИЯ И ВОЗМОЖНОСТИ РАЗВИТИЯ ОБРАБАТЫВАЮЩЕЙ ПРОМЫШЛЕННОСТИ РОССИИ
}

\author{
Комкина T.A.
}

Целью работы является анализ динамики ряда показателей промышленного производства России и сопоставление с показателями других стран на основе мировых статистических данных с иелью выявления сильных и слабых сторон развития обрабатывающей промышленности страны, перспектив дальнейшего развития.

DOI: $10.20537 /$ mce2021 econ05

Введение. Значительная доля поставок топливно-сырьевой продукции способствует возникновению зависимости экономики страны от колебаний мировой конъюнктуры, а также от форс-мажорных обстоятельств, которые могут возникать на мировых рынках. Промером может служить сложная ситуация в экономиках многих стран, возникшая в связи с текущей глобальной пандемией коронавирусной инфекции COVID-19, вызванная коронавирусом SARS-CoV-2. В сложившейся ситуации необходима выработка системы мер в области экономической политики, направленных на переход экономики страны на траекторию устойчивого развития. $[1,2,3]$. Следует отметить, что проблемы реиндустриализации затронули сферу управления, макроэкономическую политику, социальноэкономические цели и микроэкономическую политику [4].

В связи с этим интерес представляет анализ мировых статистических данных по ряду показателей промышленного производства. Для расчетов в работе использовались преимущественно данные мирового банка за период 1990-2019 гг., т.к. на их основе возможно провести сравнительный анализ по ряду показателей по странам, в том числе по укрупненным направлениям обрабатывающей промышленности (ОП), сопоставить объёмы экспорта и импорта, развитие производства высокотехнологичной продукции. Следует отметить, что имеются определенные ограничения, накладываемые наличием и объёмом статистических данных. 
В работе рассматривались следующие показатели: доля ОП (\% ВВП), доля химической промышленности в ОП (\%), доля машин и транспортного оборудования в ОП (\%), доля средних и высокотехнологичных производств промышленности в ОП (\%), доля экспорта и импорта промышленных товаров (\% от товарного экспорта) и др.

Анализ динамики изменения доли обрабатывающей промышленности в структуре ВВП по странам. По данным на 2019 г. самая большая доля ОП в ВВП среди рассмотренных стран была в Китае $27.2 \%$, Республике Корея - 25.4\%, Чехии - 22.4\%, Японии - 20.7\%, Германии - 19.4\%. В России доля обрабатывающей промышленности в ВВП составила $13.1 \%$ (см. рис. 1 ).

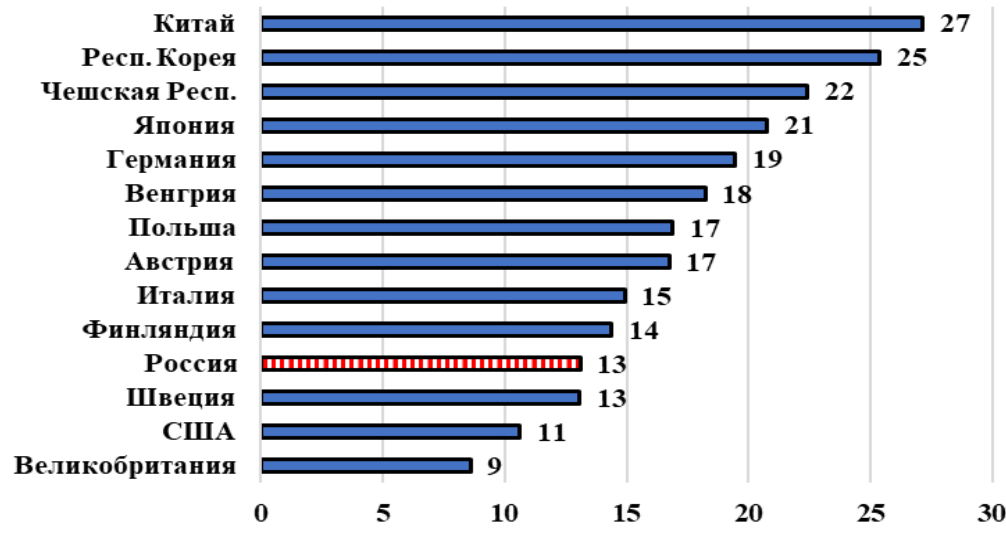

Рис. 1. Объем производства ОП (\% ВВП) по странам, 2019 гг. Источник данных: [6].

При этом если рассмотреть динамику изменения данного показателя по странам за период 2002-2019 гг., то прослеживается общее снижение доли объема ОП в ВВП рассматриваемых стран относительно других отраслей, в первую очередь секторов сферы услуг. В последние годы в развитых странах также произошло изменение отраслевой структуры экономики, снизилась доля промышленного сектора и значительно выросла доля высокотехнологичных секторов сферы услуг. 
Анализ структуры обрабатывающей промышленности по укрупненным направлениям по объему отгруженных товаров (\%) в 2018 г. показал, что наиболее значимыми видами деятельности обрабатывающих производств в РФ по удельному весу в общем объеме отгруженных товаров является производство машин и оборудования, транспорта $18.7 \%$ (уступая только производству кокса и нефтепродуктов - $23.3 \%$ и металлургическому производству - 19.2\%), а также производство пищевых продуктов - 15.2\%, химическое производство - $11.2 \%$ [5].

\section{Изменение структуры обрабатывающей промышленности по} укрупненным направлениям. На основе статистических данных Мирового банка (World Bank, отрасли ISIC 15-37 Международной стандартной отраслевой классификацией (МСОК)) можно проследить динамику изменения структуры ОП по ряду укрупненных направлений за период 1990-2018 гг.

Анализ химической промышленности России (одной из важнейших отраслей экономики) показал, что за рассматриваемый период времени произошел значительной рост доли химической промышленности в ОП, почти в два раза — $94.2 \%$ (см. табл. 1).

Таблица 1. Динамика изменения доли химической промышленности в ОП по странам, 1990-2018 гг., \%. Источник данных: [6].

\begin{tabular}{|l|c|c|c|c|c|c|c|}
\hline Страна & $\mathbf{1 9 9 0}$ & $\mathbf{1 9 9 5}$ & $\mathbf{2 0 0 0}$ & $\mathbf{2 0 0 5}$ & $\mathbf{2 0 1 0}$ & $\mathbf{2 0 1 5}$ & $\mathbf{2 0 1 8}$ \\
\hline Россия & 100 & 109.5 & 110.6 & 113.2 & 134 & 179.7 & 194.2 \\
\hline Швеция & 100 & 112.8 & 123.4 & 167.9 & 65.5 & 193.5 & 150.8 \\
\hline Финляндия & 100 & 83.2 & 67.3 & 81.2 & 114.9 & 92.9 & 149.5 \\
\hline США & 100 & 100.2 & 100.8 & 127.2 & 138.8 & 136.2 & 140 \\
\hline Италия & 100 & 125.5 & 115.1 & 109.7 & 126.9 & 128.2 & 134.3 \\
\hline Япония & 100 & 107.2 & 109.3 & 112.7 & 122.5 & 113.1 & 119.5 \\
\hline Австрия & 100 & 68.7 & 91.5 & 89.9 & 110 & 115.2 & 117.1 \\
\hline Респ. Корея & 100 & 101.3 & 103.7 & 94 & 76.3 & 111.9 & 116.7 \\
\hline Венгрия & 100 & 106.8 & 84 & 80.3 & 83.4 & 97.7 & 109.3 \\
\hline Германия & 100 & & 95.6 & 100.8 & 111.9 & 101.7 & 100.7 \\
\hline Польша & 100 & 115 & 101.6 & 98 & 112.3 & 100.8 & 90.4 \\
\hline Китай & 100 & 87 & 91.8 & 83.8 & 82.3 & 82.5 & 82.5 \\
\hline Великобритания & 100 & 99.8 & 86.8 & 99.5 & 118.1 & 76.1 & 61.3 \\
\hline
\end{tabular}

При этом следует отметить, что Россия занимает 11 место (2.1\%) от мирового объема по производству химической продукции. Лидерами 
являются США (18.6\%), Китай (15\%), Япония (8\%). В России доля импорта химической продукции составила около $20 \%$ от общего объема потребления в 2017 г. Анализ также показал, что основными ведущими направлениями химической промышленности по росту за рассматриваемый период являются агрохимия, производство синтетических смол и пластмассы.

Следует отметить, что с 1993 г. в России произошел рост, хотя и незначительный (14\%) доли производства пищевых продуктов, включая напитки и табак в ОП. Лидерами роста данного показателя за период 1990-2018 гг. являются Япония, где рост составил 48\%, Великобритания $-41.5 \%$, Италия - $30.8 \%$, США - 28.5\%. Расчеты также показали, что значительное снижение доли производства пищевых продуктов, включая напитки и табак в ОП произошло в Венгрии и Финляндии - на $28.4 \%$, в Республике Корее - на 38.2\%.

Анализ динамики изменения доли текстильного и швейного производства в ОП показал, что здесь снижение произошло во всех рассматриваемых странах. В настоящее время основной объём текстильного производства сосредоточен в развивающихся странах, имеющих в достаточном количестве сырье и дешевую рабочую силу. Российский рынок текстильного и швейного производства, включая сегмент синтетического текстиля, сохраняет большую зависимость от импорта. В сегменте швейного производства за период экономических реформ наблюдалось сокращение по всем позициям, ни по одной товарной категории к настоящему времени не удалось выйти на уровень начала 1990-х гг., отставание остается весьма значительным.

Деиндустриализация экономики негативно отразилась на машиностроительном комплексе. Расчеты показали значительное снижение доли производства машин и транспортных средств в ОП за период с 1990 по 2018 г., на 60\% (см. табл. 2). При этом в других рассматриваемых странах наблюдается значительный рост данного показателя. Лидерами роста являются такие страны, как Венгрия (141.6\%), Япония (81.5\%), Финляндия (65\%), Республика Корея (60\%). Например, на российском рынке станкоинструментальной продукции в 2016 г. отечественные производители металлорежущих станков занимали около 10\% внутреннего рынка, кузнечнопрессового оборудования - 5\%, а производители инструмента для станков около 40\% (в стоимостном выражении) [7]. 
Анализ и моделирование экономических и соџиальньх процессов - МКО - 2021

Analysis and modeling of economic and social processes - MCE - 2021

Таблица 2. Динамика изменения доли производства машин и транспортных средств в ОП по странам, 1990-2018 гг. \%. Источник данных: [6].

\begin{tabular}{|l|c|c|c|c|c|c|c|}
\hline Страна & $\mathbf{1 9 9 0}$ & $\mathbf{1 9 9 5}$ & $\mathbf{2 0 0 0}$ & $\mathbf{2 0 0 5}$ & $\mathbf{2 0 1 0}$ & $\mathbf{2 0 1 5}$ & $\mathbf{2 0 1 8}$ \\
\hline Венгрия & 100 & 79.9 & 164.2 & 182.8 & 247.7 & 265.5 & 241.6 \\
\hline Япония & 100 & 128.8 & 136.1 & 149.4 & 150.7 & 184.7 & 181.5 \\
\hline Финляндия & 100 & 134.1 & 187.6 & 185.1 & 179.1 & 152.2 & 165.0 \\
\hline Респ. Корея & 100 & 119.7 & 137.0 & 145.8 & 165.2 & 161.6 & 160.3 \\
\hline Китай & 100 & 100.1 & 90.5 & 163.6 & 157.5 & 157.7 & 157.7 \\
\hline Великобритания & 100 & 106.4 & 109.2 & 98.2 & 133.6 & 147.0 & 149.1 \\
\hline Австрия & 100 & 109.4 & 124.3 & 138.8 & 134.0 & 143.4 & 143.7 \\
\hline Швеция & 100 & 109.8 & 121.5 & 120.0 & 125.8 & 122.5 & 132.4 \\
\hline Германия & & 100.0 & 92.8 & 100.2 & 113.2 & 125.3 & 126.3 \\
\hline США & 100 & 96.6 & 131.4 & 111.0 & 125.7 & 127.9 & 126.2 \\
\hline Италия & 100 & 94.2 & 94.1 & 93.1 & 117.4 & 122.4 & 125.8 \\
\hline Польша & 100 & 86.2 & 77.0 & 84.8 & 125.5 & 119.6 & 119.6 \\
\hline Россия & 100 & 77.8 & 91.6 & 45.7 & 45.9 & 43.0 & 40.1 \\
\hline
\end{tabular}

Доля добавленной стоимости средне- и высокотехнологичной промышленности в общей добавленной стоимости обрабатывающей промышленности в России крайне низкая - около 30\%. В Республике Корее, Германии этот показатель в два раза выше (см. рис.2). Увеличение доли средних и высокотехнологичных секторов в отраслях производства отражает влияние инноваций, показывает структурные изменения в промышленности, скорость перехода от ресурсоемких и низкотехнологичных видов деятельности к высокотехнологичным направлениям.

Анализ данных по объёму импорта и экспорта промышленных товаров за 2019 г. для России показал значительную диспропорцию: импорт превысил экспорт практически в 4 раза (в 1996 г. этот показатель составлял около 1.7 раза), см. рис. 3. В расчеты включены товары в разделах SITC 5 (химические продукты), 6 (основные обрабатывающие производства), 7 (машины и транспортное оборудование) и 8 (разные промышленные товары), за исключением раздела 68 (цветные металлы). По данным 1996 г. доля импорта промышленных товаров в общем импорте составляла $45.3 \%$, экспорта - $26 \%$.

Проведенные расчеты показали, что доля экспорта высокотехнологичных товаров (\% от экспорта промышленных товаров) для России составила в 2018 г. только 11\%. Лидерами по данному показателю является Республика Корея - 36\% и Китай - 31\%. Следует отметить, что 
за период 2007-2018 гг. доля экспорта высокотехнологичных товаров в общем экспорте выросла в России на $50 \%$ (в Польше рост данного показателя составил $180 \%$, в Финляндии - $41 \%$ и в США - 61\%). Следует отметить значительную зависимость российского рынка электроники от импорта: так, доля продукции российских предприятий в электронной промышленности составила в 2017 г. 22\% (26\% - включая микроэлектронику) [8].

Анализ показал, что значительным фактором, сдерживающим развитие обрабатывающей промышленности в России, является физическая изношенность и моральное устаревание материально-технической базы предприятий. Средний показатель степени износа оборудования в 2017 г. составил более 47\% (предельно критическое значение 40\%). Расчеты показали, что степень износа ОФ с 1990 г. по 2017 г. увеличилась на 8.8\%; доля полностью изношенных ОФ с 2010 г. по 2017 г. увеличилась на $4.3 \%$.

Выводы. Проведенные расчеты показали, что отставание от других стран и снижение показателей в сегменте производства машин и оборудования, а также транспортных средств является для России критически опасным, так как этот показатель отражает способность страны самостоятельно обеспечить себя средствами производства во всех отраслях и демонстрирует индустриальную мощь страны, влияет на технологическое развитие всех отраслей.

Проведенный анализ показал значительную зависимость России от импорта промышленных товаров, а также диспропорцию соотношения импорта и экспорта по сравнению с другими странами: в России импорт превысил экспорт практически в 4 раза. При этом доля экспорта высокотехнологичных товаров в общем экспорте промышленных товаров для России составляет только $11 \%$.

На основе полученных расчетов можно сделать вывод, что предприятия обрабатывающей промышленности используют физически и морально устаревшие основные фонды, которые не заменяются новыми в необходимом объеме, имеют динамическую тенденцию к увеличению, в то же время коэффициент обновления практически не меняется. 
Анализ и моделирование экономических и сочиальных прочессов - МКО - 2021

Analysis and modeling of economic and social processes - MCE - 2021

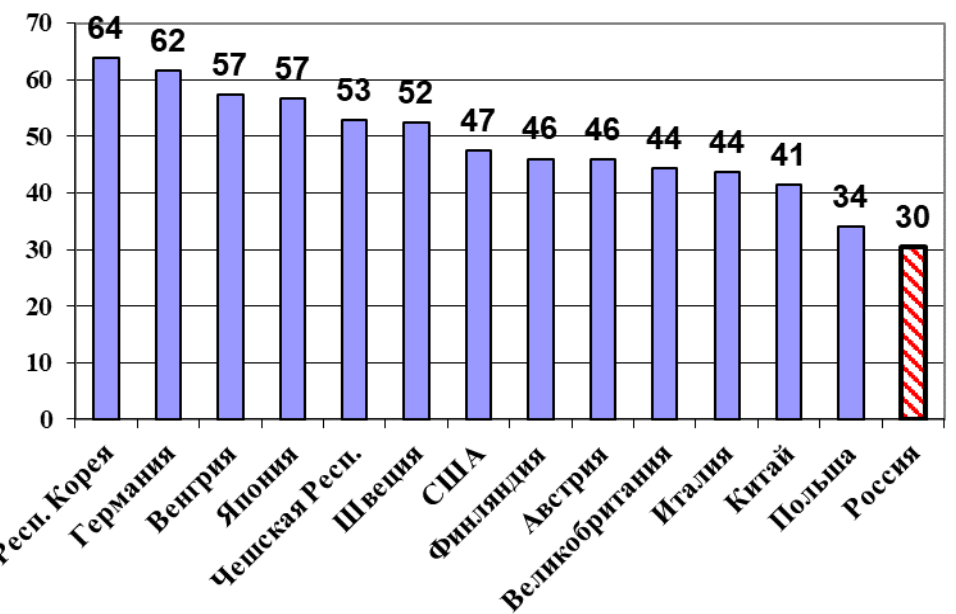

Рис. 2. Доля средне- и высокотехнологичной промышленности (включая строительство) в общей добавленной стоимости ОП (\%), 2018 г. Источник данных: [6].

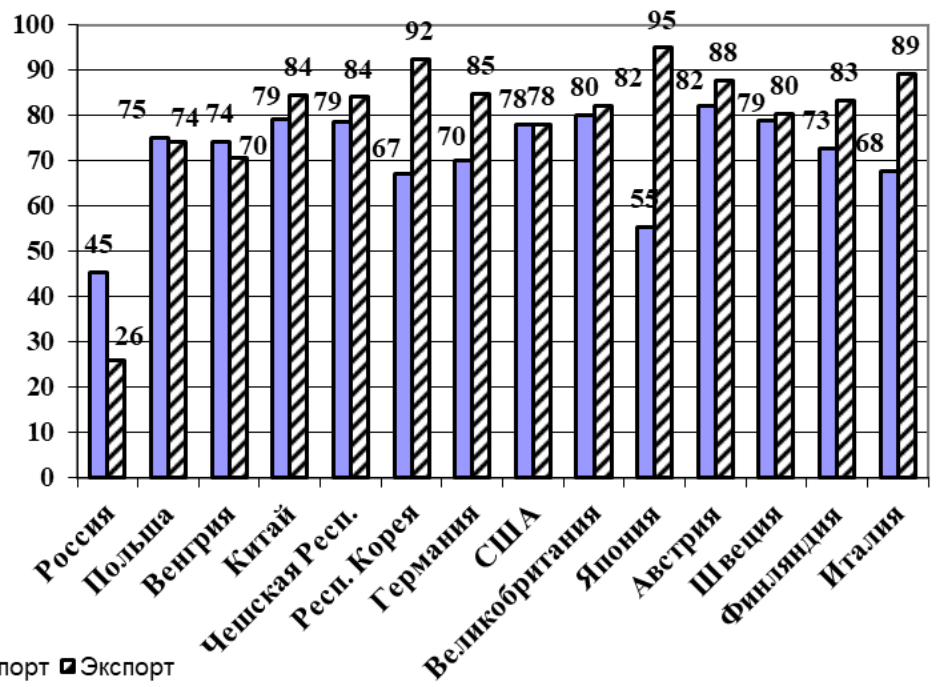

Рис. 3. Импорт-экспорт промышленных товаров, \%, 2019 г. Источник данных: [6]. 


\section{СПИСОК ЛИТЕРАТУРЫ}

1. Варшавский A.E. Развитие человеческого капитала: уроки коронавируса недопустимость проблемных инноваций в управлении // Научные труды ВЭО России. Т. № 3 (223), 2020. С. 228-236. DOI: 10.38197/2072-2060-2020223-3-228-236.

2. Клейнер Г. Б. Системная перезагрузка российской экономики: ключевые направления и перспективы / Г. Б. Клейнер // Научные труды ВЭО России. T. № 3 (223), 2020. C. 111-122. DOI: 10.38197/2072-2060-2020-223-3-111-122

3. Варшавский А.Е. Проблемы социально-экономического развития страны после завершения активной фазы борьбы с коронавирусом // Научнопрактический журнал "Кониепиии". 2020. №1(39). C.3-17. DOI: 10.34705/KO.2020.39.1.001

4. Варшавский A.Е. Макро- и микроэкономические проблемы реиндустриализации России: пути решения // Экономическое возрождение России. 2018. №1. C.23-32.

5. Российский статистический ежегодник. 1990-2019. URL: https://rosstat.gov.ru/folder/210/document/12994

6. Сайт Группы Всемирного Банка. URL: https://data.worldbank.org

7. Яркин А.П., Комкина Т.А. Анализ статистических данных стратегически важных укрупненных направлений обрабатывающих производств // Научно-практический журнал "Конщепщии". 2020. №1(39). C. 76-81. DOI: 10.34705/KO.2020.39.1.009.

8. Стратегия развития электронной промышленности до 2030 года, Минпромторг России. URL:

http://minpromtorg.gov.ru/docs/\#!strategiya_razvitiya_elektronnoy_promyshlen nosti_rossiyskoy_federacii_na_period_do_2030_goda1233

\section{RESOURCE RESTRICTIONS AND POSSIBILITIES FOR DEVELOPMENT OF THE PROCESSING INDUSTRY IN RUSSIA}

\section{Komkina T.A.}

The aim of the work is to analyze the dynamics of a number of industrial production indicators in Russia and to compare them with those of other countries based on world statistics in order to identify the strengths and weaknesses of the development of the country's manufacturing industry and the prospects for further development. 